\title{
SHORT-TERM EFFECTS OF AIR POLLUTION ON CARDIOVASCULAR MORTALITY IN ELDERLY IN NIŠ, SERBIA
}

\author{
Aleksandra Stanković, Dragana Nikić, Maja Nikolić, Dragan Bogdanović \\ Medical Faculty of Niš, Public Health Institute Niš, Serbia
}

\begin{abstract}
SUMMARY
The short-term effects of air pollution on cardiovascular mortality in elderly were investigated in Niš, during the 2001-2005. Daily measurements of black smoke (BS) and sulphur dioxide $\left(\mathrm{SO}_{2}\right)$, as well as the daily number of cardiovascular death among person $\geq 65 \mathrm{yrs}$ of age, were collected. Generalized linear model extending Poisson regression was applied. The effects of time trend, seasonal variations, day of week, temperature, relative humidity and barometric pressure were analysed. The results did not support findings from previous studies that had shown an increase in the number of cardiovascular death in elderly in association with air pollution.
\end{abstract}

Key words: elderly, cardiovascular death, mortality, black smoke, sulphur dioxide

Address for correspondence: A. Stanković, Medical Faculty of Niš, Public Health Institute Niš, Zorana Đinđića 50, 18000 Niš, Serbia.

E-mail: cekrk@medianis.net

\section{INTRODUCTION}

Epidemiological evidence in the last decade confirmed that elevated concentrations of air pollution contributed to the adverse cardiovascular health effects (1-5). These effects refer to cardiovascular morbidity, hospitalization and mortality.

The potential biological mechanisms of influence air pollution on cardiovascular system have two possible interlinksinflammatory response and abnormal autonomic control (6-8). Inflammatory response leads to the release of prothrombotic and inflammatory cytokines into the circulation resulting in plaque rupture. Abnormal autonomic control leads to an increased risk of arrhythmia in susceptible patients.

Many air pollutants are in the relationship with cardiovascular damage but of special interest are particulate matters with different aerodynamic diameter (9-11). The time series data suggest that an increase in particulate pollution of $10 \mu \mathrm{g} / \mathrm{m}^{3}$ is associated with an increased cardiovascular mortality of about $1.4 \%(12,13)$. The elderly are the population group which is more sensitive to effects of air pollution (14-17).

This is the second study providing quantitative estimates of the short-term effects of air pollution on mortality in our country. The first one, by Bogdanović et al. (18), has shown that cardiovascular and total non-accidental mortality are related to ambient black smoke (BS) concentrations.

This paper reports the results on the effects on daily BS and sulphur dioxide $\left(\mathrm{SO}_{2}\right)$ on cardiovascular mortality among person $\geq 65$ yrs in Niš.

\section{MATERIAL AND METHODS}

The study area is the city of Niš, the second biggest city in Serbia. The urban city area covers $32 \mathrm{~km}^{2}$ with population of around 171,000 inhabitants. A major source of air pollution is fuel combustion including motor vehicle emissions and residential wood, coal and oil burning.

Daily cardiovascular mortality data between 2001 and 2005 were obtained from the Republic Institute for Statistics in charge of coding the medical causes of death according to the International Classification of Diseases $-10^{\text {th }}$ Revision (I00-I99) among person $\geq 65$ years old.

Air pollution data were provided by the Public Health Institute of Niš. Daily concentrations of $\mathrm{BS}$ and $\mathrm{SO}_{2}$ were monitored using the local monitoring network. BS $\left(\mu \mathrm{g} / \mathrm{m}^{3}\right)$ was measured by the refractometry method and $\mathrm{SO}_{2}\left(\mu \mathrm{g} / \mathrm{m}^{3}\right)$ by spectrophotometer. Missing air pollution values for $6 \%$ days of the period were treated as being missing completely at random and were dropped from the analyses.

The concentrations of the outdoor air pollutants sulphur dioxide and black smoke, were measured for 24 hours a day during the period from 2001 to 2005 . The sampling protocol was carried out by well trained personnel. The laboratory experiments on sulphur dioxide and black smoke were done according to the Regulation of Guideline Values of Imission (Official Register Republic of Serbia 54/92).

The ambient level of black smoke was measured by the reflectance. The sampling was performed by the means of a pump 
operating with a flow rate of 1 1/min through Whattman No. 1 paper filters.

The air concentration of sulphur dioxide was determined simultaneously with that of black smoke. A measured volume of air was bubbled through solution of potassium mercury tetrachloride. The sulphur dioxide which is presented in the air stream reacted with the solution to form a stable monochlorosulfonatomercurate. During the subsequent analysis, this complex was brought into reaction with acid-bleached pararosaniline dye and formaldehyde yielding intensely coloured pararosaniline methyl sulphuric acid. The optical density of this species was determined spectrophotometrically at $548 \mathrm{~nm}$ and was directly related to the collected amount of sulphur dioxide. The total volume of the air sample was determined from the flow rate and the sampling time. The concentration of sulphur dioxide in the ambient air was computed and expressed in $\mu \mathrm{g} / \mathrm{m}^{3}$ and the lower limit of detection was $1.7 \mu \mathrm{g} / \mathrm{m}^{3}$.

The daily mean temperature, the mean relative humidity and the mean barometric pressure values for the same period were obtained from Republic Meteorological Department.

Generalized linear model (GLM) extending Poisson regression was applied allowing over dispersion. This model used mortality counts as the response variable, the natural cubic splines of the calendar time, temperature, relative humidity and barometric pressure, the day of week and season as indicator variables, and air pollution as predictor variable.

To construct the model individual lag 0 (value on a current day) for relative humidity, barometric pressure, $\mathrm{BS}$ and $\mathrm{SO}_{2}$ were used. For temperature individual lag 0 and lag $0-3$ (average of values on a current day and three days earlier) were used, both. The model fitting was based on Akaike Information Criteria (AIC). The degrees of freedom for natural spline functions of time and weather variables influence approximation that gave the smallest AIC value were selected. The pollutants were fitted as linear term. Analyses were done using S-PLUS 2000 software. The specific model formulation for cardiovascular mortality is given below.

\section{Persons of All Ages}

$\mathrm{E}[\log (Y i)]=\mathrm{a}+\mathrm{ns}($ calendar time, $\mathrm{df}=30)+$ indicator (season) + indicator $($ day of week $)+\mathrm{ns}\left(\right.$ mean temperature $\left.{ }_{\mathrm{lag}=0}, \mathrm{df}=4\right)$ $+\mathrm{ns}\left(\right.$ mean temperature $\left.{ }_{\mathrm{lag}=0-3}, \mathrm{df}=4\right)+\mathrm{ns}$ (mean relative humidity$\left.{ }_{\text {lag }=0}, \mathrm{df}=2\right)+\mathrm{ns}\left(\right.$ mean air pressure lag $\left.=0_{0}, \mathrm{df}=3\right)+$ air pollution $_{\text {lag }=0}$

\section{Persons Older than 65 Years}

$\mathrm{E}[\log (Y i)]=\mathrm{a}+\mathrm{ns}($ calendar time, $\mathrm{df}=30)+$ indicator (season) + indicator (day of week) $+\mathrm{ns}\left(\right.$ mean temperature $\left.{ }_{\text {lag }=0}, \mathrm{df}=4\right)+\mathrm{ns}$ (mean temperature $\left.{ }_{\text {lag }=0-3}, \mathrm{df}=4\right)+\mathrm{ns}$ (mean relative humidity $\mathrm{lag}=0_{0}$, $\mathrm{df}=2)+\mathrm{ns}\left(\right.$ mean air pressure $\left.\mathrm{lag}=0_{0}, \mathrm{df}=2\right)+$ air pollution $_{\operatorname{lag}=0}$

where $Y i$ are daily mortality counts, $a$ is the intercept, $n s$ denotes a natural cubic functions of a covariates, and $d f$ represents the number of degrees of freedom.

\section{RESULTS}

Table 1 shows the daily number of all age cardiovascular deaths, cardiovascular deaths among person $\geq 65 \mathrm{yrs}$, pollutants concentrations and weather data. During the 5 years, there were 4,818 all age cardiovascular deaths in the city of Niš, and 4,006 cardiovascular deaths among person $\geq 65$ yrs. The daily mean number of all age cardiovascular deaths was $2.64 \pm 1.69(0$ to 10 ) and $2.19 \pm 1.51$ ( 0 to 3 ) among person $\geq 65$ yrs. The daily mean level for BS was $22.83 \pm 21.82 \mu \mathrm{g} / \mathrm{m}^{3}$, minimum $1.00 \mu \mathrm{g} /$ $\mathrm{m}^{3}$ and maximum $225.00 \mu \mathrm{g} / \mathrm{m}^{3}$. The daily mean level for $\mathrm{SO}_{2}$ was $14.69 \pm 12.57 \mu \mathrm{g} / \mathrm{m}^{3}$, minimum $1.00 \mu \mathrm{g} / \mathrm{m}^{3}$ and maximum $107.00 \mu \mathrm{g} / \mathrm{m}^{3}$.

The Pearson's correlation coefficients between air pollutants and meteorological variables are presented in Table 2.

Table 3 and Fig. 1 summarize the results of $\mathrm{SO}_{2}$ influence on all age cardiovascular deaths and among person $\geq 65$ yrs. According to the results of unipolutant regression model, the risk of cardiovascular deaths because of an increase of $10 \mu \mathrm{g} / \mathrm{m}^{3}$ in $\mathrm{SO}_{2}$ in all age increases by $2,50 \%(\mathrm{OR}=1,02503 ; 95 \% \mathrm{CI}: 0,99020$ to $1,06109)$, and among person $\geq 65$ yrs by $2,83 \%(\mathrm{OR}=1,02834$; $95 \%$ CI: 0,99029 to 1,06785), but was not significant. Estimated OR of bio pollutant regression model for among person $\geq 65 \mathrm{yrs}$ was 1,01812 (95\% CI: 0,9818 to1,05578), that is, an increase of $10 \mu \mathrm{g} / \mathrm{m}^{3}$ in $\mathrm{SO}_{2}$ augmented $1,81 \%$ the probability of death on a given day, this again being not significant.

Table 4 and Fig. 2 summarize the results of BS influence on cardiovascular deaths among person $\geq 65$ yrs. Estimated OR of unipolutant regression model for among person $\geq 65$ yrs was 1,01312 (95\% CI: 0,99581 to 1,03072$)$, and estimated OR of bipolutant model was 1,01012 (95\% CI: 0,99195 to 1,02863).

Table 1. Summary statistics of daily data in Niš

\begin{tabular}{|l|c|c|c|c|c|c|c|}
\hline & Mean & SD & Min & 25\% & Median & $75 \%$ & Max \\
\hline All age cardiovascular deaths $(\mathrm{n})$ & 2.64 & 1.69 & 0 & 1 & 2 & 4 & 10 \\
\hline $\begin{array}{l}\text { Cardiovascular deaths among person } \\
\geq 65 \text { yrs }(\mathrm{n})\end{array}$ & 2.19 & 1.51 & 0 & 1 & 2 & 3 & 9 \\
\hline $\mathbf{B S}\left(\boldsymbol{\mu g} / \mathrm{m}^{3}\right)$ & 22.83 & 21.82 & 1.00 & 9.50 & 17.00 & 26.50 & 225.00 \\
\hline $\mathbf{S O}_{2}\left(\boldsymbol{\mu g} / \mathrm{m}^{3}\right)$ & 14.69 & 12.57 & 1.00 & 6.00 & 11.50 & 19.00 & 107.00 \\
\hline Temperature $\left({ }^{\circ} \mathrm{C}\right)$ & 12.10 & 8.80 & -11.60 & 4.90 & 12.80 & 19.40 & 30.50 \\
\hline Humidity $(\%)$ & 70.33 & 13.08 & 26.00 & 6.10 & 71.00 & 80.00 & 108.00 \\
\hline Air pressure $(\mathrm{mBar})$ & 993.80 & 67.00 & 966.20 & 989.60 & 993.30 & 997.90 & 1014.80 \\
\hline
\end{tabular}


Table 2. Correlation between air pollutants and weather variables

\begin{tabular}{|l|c|c|c|c|}
\hline Parameter & Humidity & Air pressure & Temperature & $\mathrm{SO}_{2}$ \\
\hline $\mathrm{BS}$ & $0.181^{\star \star}$ & $0.197^{\star \star}$ & $-0.305^{\star \star}$ & $0.389^{\star \star}$ \\
\hline $\mathrm{SO}_{2}$ & -0.007 & $0.344^{* \star}$ & $-0.556^{\star \star}$ & \\
\hline Temperature & $-0.512^{\star \star}$ & $-0.313^{\star \star}$ & & \\
\hline Air pressure & 0.020 & & & \\
\hline
\end{tabular}

** Significant at the 0.01 level

Table 3. ORs $(95 \% \mathrm{Cls}) / 10 \mu \mathrm{g} / \mathrm{m}^{3}$ increase in concentration of $\mathrm{SO}_{2}$ for daily numbers of all age cardiovascular deaths and among person $\geq 65 \mathrm{yrs}$

\begin{tabular}{|l|c|c|c|c|c|c|}
\hline \multirow{2}{*}{ Model } & Age & $\boldsymbol{\beta}$ & SE & OR & Lower 95\% & Upper 95\% \\
\hline \multirow{2}{*}{ Unipolutant } & Total & 0.02473 & 0.01764 & 1.02503 & 0.99020 & 1.06109 \\
\cline { 2 - 7 } & $\geq 65$ & 0.02795 & 0.01923 & 1.02834 & 0.99029 & 1.06785 \\
\hline \multirow{2}{*}{ Bipolutant } & Total & 0.02128 & 0.02020 & 1.02150 & 0.98185 & 1.06276 \\
\cline { 2 - 7 } & $\geq 65$ & 0.01796 & 0.01853 & 1.01812 & 0.98180 & 1.05578 \\
\hline
\end{tabular}

Table 4. ORs (95\% Cls) $/ 10 \mu \mathrm{g} / \mathrm{m}^{3}$ increase in concentration of BS for daily numbers of all age cardiovascular deaths and among person $\geq 65$ yrs

\begin{tabular}{|l|c|c|c|c|c|c|}
\hline \multirow{2}{*}{ Model } & Age & $\boldsymbol{\beta}$ & SE & OR & Lower 95\% & Upper 95\% \\
\hline \multirow{3}{*}{ Unipolutant } & total & 0.01268 & 0.00806 & 1.01276 & 0.99689 & 1.02889 \\
\cline { 2 - 7 } & $\geq 65$ & 0.01303 & 0.00879 & 1.01312 & 0.99581 & 1.03072 \\
\hline \multirow{2}{*}{ Bipolutant } & total & 0.01017 & 0.00849 & 1.01022 & 0.99354 & 1.02718 \\
\cline { 2 - 7 } & $\geq 65$ & 0.01007 & 0.00926 & 1.01012 & 0.99195 & 1.02863 \\
\hline
\end{tabular}

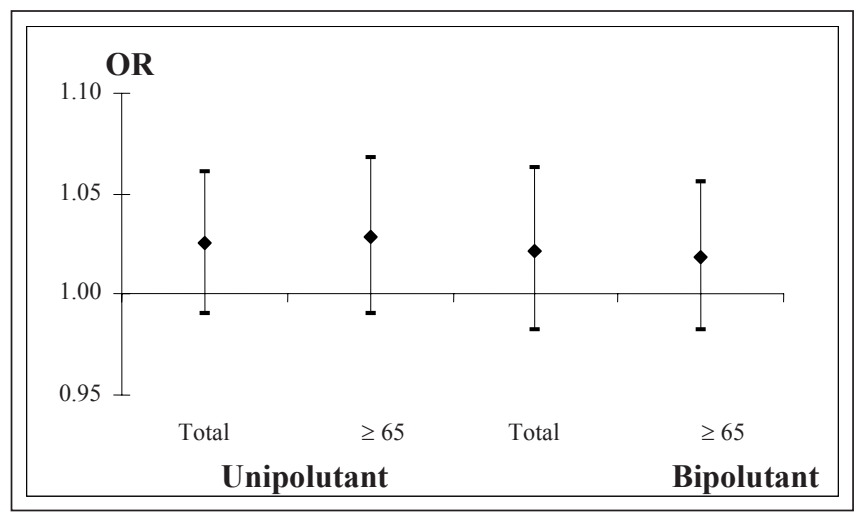

Fig. 1. Association between $\mathrm{SO}_{2}$ concentration and the number of all age cardiovascular deaths and among person $\geq 65 \mathrm{yrs}$.

\section{DISCUSSION}

This mortality time series study have shown, that all age cardiovascular mortality and among person $\geq 65$ yrs are not related to ambient air pollutants concentrations. There is a risk of cardiovascular death with increase of $10 \mu \mathrm{g} / \mathrm{m}^{3}$ in $\mathrm{SO}_{2}$ and BS, but it is statistically insignificant.

Low quality of the fuel and vehicles results in incomplete fossil burning during the heating and traffic in our country. Growing epidemiological evidence suggests that exposure to the particulate matter such as $\mathrm{PM}_{10}$ and $\mathrm{PM}_{2.5}$ causes negative health effects. Due to shortage of the equipment for measuring this particulate matter we use BS measurement data for calculation. However, WHO documents (19) indicate that BS could serve as a useful marker in epidemiological studies. Levels of $\mathrm{BS}$ and $\mathrm{SO}_{2}$ measured in our

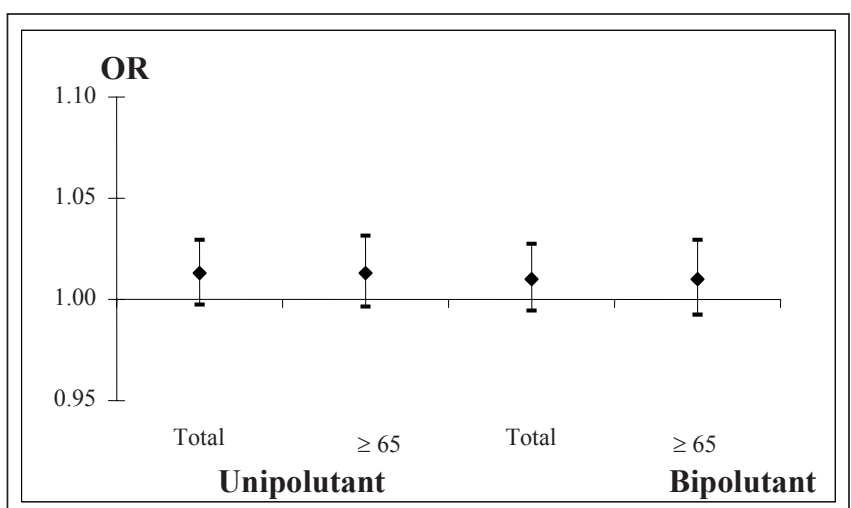

Fig. 2. Association between BS concentration and the number of cardiovascular deaths in all age and in person $\geq 65 \mathrm{yrs}$.

study were not very high, and were generally below the national standard $\left(50 \mu \mathrm{g} / \mathrm{m}^{3}\right)$.

The majority of the published studies have found significant associations between a $10 \mu \mathrm{g} / \mathrm{m}^{3}$ increase in air pollutants and increase in daily number of death (20-22). Zmirou et al. (23) found that daily deaths of cardiovascular conditions increased $2 \%$ with $\mathrm{BS}$ and $4 \%$ with $\mathrm{SO}_{2}$. In a study in the city of Dublin, Ireland (24), a reduction in BS concentration by $35.6 \mu \mathrm{g} / \mathrm{m}^{3}$ was associated with a $10.3 \%$ decrease in annual cardiovascular mortality.

There is lot of evidence that air pollution has harmful effect on the elderly population. The results of the APHEA2 project (25) indicated that the per cent increase of daily number of death associated with a $10 \mu \mathrm{g} / \mathrm{m}^{3}$ increase in $\mathrm{PM}_{10}$ was in elderly $0.8 \%$ and the corresponding number for BS was $0.6 \%$. In the elderly, a $3-4 \%$ increase in daily deaths for all causes and for cardiovascular 
diseases was associated with an increase in fine particulate matter and in sulphur dioxide from the 10th to the 90th percentile (26). In 20 U.S. cities (27) the level of $\mathrm{PM}_{10}$ is associated with the rate of death from all causes and from cardiovascular and respiratory illnesses. The estimated increase in the relative rate of death from cardiovascular and respiratory causes was $0.68 \%(95 \%$ posterior interval, 0.20 to $1.16 \%$ ) for each increase in the $\mathrm{PM}_{10}$ level of $10 \mu \mathrm{g} / \mathrm{m}^{3}$. Levels of $\mathrm{SO}_{2}$ were not significantly related to the mortality rate.

In two French cities no coherent results were found between $\mathrm{SO}_{2}$ pollution and cardiovascular deaths (28). Ballester et al. (29) found that the estimated relative risk (RR) of dying corresponding to a $10 \mu \mathrm{g} / \mathrm{m}^{3}$ increase in mean daily BS over the whole study period was 1.009 ( $95 \%$ CI: 1.003, 1.015). For mortality in the group aged more than 70 years and for cardiovascular mortality, the RRs were 1.008 (95\% CI: 1.001, 1.016) and 1.012 (95\% CI: 1.003, 1.022) respectively. The association with $\mathrm{SO}_{2}$ was less clear: it was evident during the warm season only. The estimated RRs in this case were 1.007 (95\% CI: $0.999,1.015)$ for total mortality, 1.009 (95\% CI: $1.00,1.21)$ for total mortality in those older than 70 , and 1.012 (95\% CI: 0.995, 1.026) for cardiovascular deaths.

The associations which could be explained partially by the small number of pollution measurements available for the period analyzed were statistically insignificant. The results were also dependent on season and type of climate. In our country the climate is moderate continental and higher air pollutants effects are generally found in warmer and drier climates. The results from 29 European cities within due to APHEA2 project (30) suggest that in population with higher underlying mortality rate due to effects of PM on the elderly are smaller.

However, in response to air pollution exposure, different age groups may respond differently. Who is at risk and who is more susceptible to the adverse health effects of air pollution are important questions which have not been fully clarified $(31,32)$.

\section{REFERENCES}

1. Brunekreef B, Holgate ST. Air pollution and health. Lancet. 2002 Oct 19;360(9341):1233-42.

2. Schwartz J. Air pollution and blood pressure markers of cardiovascular risk. Environ Health Perspect. 2001 Jun;109 Suppl 3:405-9.

3. Peters A, Dockery DW, Muller JE, Mittlemann MA. Increased particulate air pollution and the triggering of myocardial infarction. Circulation. 2001 Jun 12;103(23):2810-5.

4. Gold DR, Litonjua A, Schwartz J, Lovett E, Larson A, Nearing B, et al. Ambient pollution and heart rate variability. Circulation. 2000 Mar 21;101(11):1267-73.

5. Folsom AR, Aleksic N, Park E, Salomaa V, Juneja H, Wu KK. Prospective study of fibrinolytic factors and incident coronary heart disease: the Atherosclerosis Risk in Communities (ARIC) Study. Arterioscler Thromb Vasc Biol. 2001 Apr;21(4):611-7.

6. Widdicombe J, Lee LY. Airway reflexes, autonomic function, and cardiovascular responses. Environ Health Perspect. 2001 Aug;109 Suppl 4:579-84.

7. Utell MJ, Frampton MW, Zareba W, Devlin RB, Cascio WE. Cardiovascular effects associated with air pollution: potential mechanisms and methods of testing. Inhal Toxicol. 2002 Dec;14(12):1231-47.

8. Kelly FJ. Oxidative stress: it's role in air pollution and adverse health effects. Occup Environ Med. 2003 Aug;60(8):612-6.

9. Dockery DW. Epidemiologic evidence of cardiovascular effects of particulate air pollution. Environ Health Perspect. 2001 Aug;109 Suppl 4:483-6.
10. Ibald-Mulli A, Wichmann HE, Kreyling W, Peters A. Epidemiological evidence on health effects of ultrafine particles. J Aerosol Med. 2002; 15(2):189-201.

11. Pope CA $3^{\text {rd }}$. Epidemiology of fine particulate air pollution and human health: biological mechanisms and who is at risk? Environ Health Perspect. 2000 Aug; 108 Suppl 4:713-23.

12. Dockery DW, Pope CA $3^{\text {rd }}$, Xu X, Spengler JD, Ware JH, Fay ME, et al. An association between air pollution and mortality in six U.S. cities. N Engl J Med. 1993 Dec 9;329(24):1753-9.

13. Schwartz J. What are people dying of on high air pollution days? Environ Res. 1994 Jan;64(1):26-35.

14. Goldberg MS, Burnett RT, Bailar JC $3^{\text {rd }}$, Tamblyn R, Ernst P, Flegel K, et al. Identification of persons with cardiorespiratory conditions who are at risk of dying from the acute effects of ambient air particles. Environ Health Perspect. 2001 Aug;109 Suppl 4:487-94.

15. Pope CA $3^{\text {rd }}$, Burnett RT, Thun MJ, Calle EE, Krewski D, Ito K, et al. Lung cancer, cardiopulmonary mortality, and long-term exposure to fine particulate air pollution. JAMA. 2002 Mar 6;287(9):1132-41.

16. Routledge HC, Ayres JG, Townend JN. Why cardiologist should be interested in air pollution. Heart. 2003 Dec;89(12):1383-8.

17. Bateson TF, Schwartz J. Who is sensitive to the effects of particulate air pollution on mortallity? A case-crossover analysis of effect modifiers. Epidemiology. 2004 Mar;15(2):143-9.

18. Bogdanovic DC, Nikic DS, Milosevic ZG, Stankovic AM. Black smoke air polution and daily non-accidental mortality in Nis, Serbia. Cent Eur J Med. 2006 Sep;1(3):292-7.

19. Health aspects of air aollution with aarticulate matter, ozone and nitrogen dioxide. Report on a WHO Working Group; 2003 Jan 13-15; Bonn, Germany. Copenhagen: WHO; 2003.

20. Hedley AJ, Wong CM, Thach TQ, Ma S, Lam TH, Anderson HR. Cardiorespiratory and all-cause mortality after restrictions on sulphur content of fuel in Hong Kong: an intervention study. Lancet. 2002 Nov 23;360(9346):1646-52.

21. Kwon HJ, Cho SH, Nyberg F, Pershagen G. Effects of ambient air pollution on daily mortality in a cohort of patients with congestive heart failure. Epidemiology. $2001 \mathrm{Jul} ; 12(4): 413-9$.

22. Hoek G, Brunekreef B, Goldbohm S, Fischer P, van den Brandt PA. Association between mortality and indicators of traffic-related air pollution in the Netherlands: a cohort study. Lancet. 2002 Oct 19;360(9341):1203-9.

23. Zmirou D, Schwartz J, Saez M, Zanobetti A, Wojtyniak B, Touloumi G, et al. Time-series analysis of air polution and cause-specific mortality. Epidemiology. 1998 Sep;9(5):495-503.

24. Clancy L, Goodman P, Sinclair H, Dockery DW. Effect of air-pollution control on death rates in Dublin, Ireland: an intervention study. Lancet. 2002 Oct 19;360(9341):1210-4.

25. Aga E, Samoli E, Touloumi G, Anderson HR, Cadum E, Forsberg B, et al. Short-term effects of ambient particles on mortality in the elderly: results from 28 cities in the APHEA2 project. Eur Respir J. 2003 May;21:S28-33.

26. Gouveia N, Fletcher T. Time series analysis of air pollution and mortality: effects by cause age and socio-economic status. J Epidemiol Community Health. 2000 Oct;54(10):750-5.

27. Samet JM, Dominici F, Curriero FC, Coursac I, Zeger SL. Fine particulate air pollution and mortality in 20 U.S. cities, 1987-1994. N Engl J Med. 2000 Dec 14;343(24):1742-9.

28. Derriennic F, Richardson S, Mollie A, Lellouch J. Short-term effects of sulphur dioxide pollution on mortality in two French cities. Int J Epidemiol. 1989 Mar;18(1):186-97.

29. Ballester F, Corella D, Perez-Hoyos S, Hervas A. Air pollution and mortality in Valencia, Spain: a study using the APHEA methodology. J Epidemiol Community Health. 1996 Oct;50(5):527-33.

30. Katsouyanni K, Touloumi G, Samoli E, Gryparis A, Le Tertre A, Monopolis $\mathrm{Y}$, et al. Confounding and effect modification in short-term effects of ambient particles on total mortality: results from 29 European cities within the APHEA2 project. Epidemiology. 2001 Sep;12(5):521-31.

31. Zanobetti A, Schwartz J, Gold D. Are there sensitive subgroups for the effects of airborne particles? Environ Health Perspect. 2000 Sep;108(9):841-5.

32. Loomis D, Castillejos M, Gold DR, McDonnell W, Borja-Aburto VH. Air pollution and infant mortality in Mexico City. Epidemiology. 1999 Mar;10(2):118-23. 